\title{
Endogenous Glucocorticoids Are Essential for Maintaining Prefrontal Cortical Cognitive Function
}

\author{
Kazushige Mizoguchi, ${ }^{1}$ Atsushi Ishige, ${ }^{1}$ Shuichi Takeda, ${ }^{1}$ Masaki Aburada, ${ }^{1}$ and Takeshi Tabira ${ }^{2}$ \\ ${ }^{1}$ Pharmacology Department, Central Research Laboratories, Tsumura and Company, Ami-machi, Inashiki-gun, Ibaraki 300-1192, Japan, and ${ }^{2}$ National \\ Institute for Longevity Sciences, Morioka, Obu, Aichi 474-8522, Japan
}

Glucocorticoid hormones are important in the maintenance of many brain functions. Although their receptors are distributed abundantly throughout the brain, including the prefrontal cortex (PFC), it is not clear how glucocorticoid functions, particularly with regard to cognitive processing in the PFC. There is evidence of PFC cognitive deficits such as working memory impairment in several stressrelated neuropsychiatric disorders, including depression, schizophrenia, and Parkinson's disease. Disruption of the hypothalamopituitary-adrenal (HPA) system, which is characterized by attenuated glucocorticoid negative feedback, is also observed. In rats, chronic stress induces working memory impairment as a result of decreased dopaminergic transmission in the PFC. These chronically stressed rats also show HPA disruption; this is caused in part by a reduced glucocorticoid response in the PFC. These findings implicate reduced glucocorticoid actions in working memory impairment. In the present study, we examined the effects of the suppression of endogenous glucocorticoids by adrenalectomy (ADX) on working memory in rats and explored the involvement of PFC dopaminergic activities in memory. The ADX impaired working memory, decreased dopamine release, and upregulated $D_{1}$ receptors in the PFC. These dysfunctions were prevented by corticosterone replacement that reproduced normal physiological plasma levels, indicating that suppression of glucocorticoids causes these dysfunctions. Moreover, the ADX-induced working memory impairment was ameliorated by intra-PFC infusions of a $D_{1}$ receptor agonist, SKF 81297 . Thus, suppression of glucocorticoids impaired working memory through a $D_{1}$ receptormediated hypodopaminergic mechanism in the PFC. This finding indicates that endogenous glucocorticoids are essential for maintaining PFC cognitive function and suggests that HPA disruption contributes to PFC cognitive deficits.

Key words: adrenalectomy; glucocorticoid; dopamine; $\mathrm{D}_{1}$ receptor; working memory; prefrontal cortex

\section{Introduction}

Glucocorticoid hormones are secreted from the adrenal cortex after activation of the hypothalamo-pituitary-adrenal (HPA) axis, under conditions such as a stressful situation (Miller et al., 1992). These hormones have an important role in maintaining many brain functions. Indeed, glucocorticoid receptors (GRs) are distributed abundantly throughout the brain, including the prefrontal cortex (PFC) (Fuxe et al., 1985; Diorio et al., 1993). However, the role of glucocorticoids, particularly in PFC cognitive function, is not fully understood.

Clinical, neuropsychological, and neuroimaging studies have indicated that PFC-related cognitive deficits, such as working memory impairment, are involved in several stress-related neuropsychiatric disorders, including depression, schizophrenia, and Parkinson's disease (Deutch, 1993; Dolan et al., 1994; Fibiger, 1995; Drevets et al., 1997). In animals, reduced PFC do-

Received Jan. 9, 2004; revised April 20, 2004; accepted April 27, 2004

This work was partially supported by the Japan Health Sciences Foundation. We thank M. Hiruta for the construction of the T-maze apparatus and Drs. M. Yuzurihara and Y. Kase for their kind support and helpful comments during the present study.

Correspondence should be addressed to K. Mizoguchi, Pharmacology Department, Central Research Laboratories, Tsumura and Company, 3586 Yoshiwara, Ami-machi, Inashiki-gun, Ibaraki 300-1192, Japan. E-mail: mizoguchi_kazushige@mail.tsumura.co.jp.

DOI:10.1523/JNEUROSCI.0086-04.2004

Copyright $\odot 2004$ Society for Neuroscience $\quad$ 0270-6474/04/245492-08\$15.00/0 paminergic functions or a blockade of dopamine (DA) receptors in the PFC impair working memory (Brozoski et al., 1979; Simon et al., 1980; Bubser and Schmidt, 1990). This involvement of the dopaminergic system has been confirmed by pharmacological studies; several antidepressants increase DA levels in the PFC (Tanda et al., 1994). Agents such as bupropion that enhance dopaminergic transmission have been used successfully as antidepressants (Calabrese and Markovitz, 1991). Moreover, raising DA levels by administration of L-dopa in patients with Parkinson's disease improves their working memory impairment (Lange et al., 1992). However, if the dosage is too high, L-dopa occasionally worsens cognitive performance in patients. Thus, PFC dopaminergic dysfunction is thought to underlie PFC cognitive deficits.

In addition, abnormal glucocorticoid secretion is evident in patients with depression, schizophrenia, and Parkinson's disease. Endogenous glucocorticoids or treatment with synthetic glucocorticoids (e.g., dexamethasone) negatively regulate their secretion, and dexamethasone-mediated negative feedback resistance is often observed in these disorders (Rabey et al., 1990; Pariante et al., 1995; Plocka-Lewandowska et al., 2001). This disruption of the HPA system is related to some of the depressive symptoms, including cognitive deficits (Steckler et al., 1999).

Thus, both PFC cognitive deficits and HPA disruption are involved in several stress-related neuropsychiatric disorders. In 
rats, chronic stress induced working memory impairments as a result of decreased dopaminergic transmission in the PFC (Mizoguchi et al., 2000). These chronically stressed rats also showed HPA disruption (Mizoguchi et al., 2001). These findings suggest that PFC cognitive deficits and HPA disruption may be related. The PFC is part of the HPA negative feedback system, along with the hypothalamus and hippocampus. For example, glucocorticoids placed locally within the PFC can decrease plasma corticosterone (CORT) levels (Diorio et al., 1993). Considering that chronic stress-induced HPA disruption is partially caused by a reduced glucocorticoid response in the PFC (Mizoguchi et al., 2003) and that dopaminergic activity in the PFC is positively regulated by glucocorticoids (Imperato et al., 1989), we hypothesized that endogenous glucocorticoids have an important role in the maintenance of PFC cognitive function, and reduced glucocorticoid action leads to PFC dysfunction. To test this hypothesis, endogenous glucocorticoids were suppressed by adrenalectomy (ADX) (i.e., shutdown of glucocorticoid actions), and the effects of this suppression on working memory and dopaminergic activity in the PFC were examined.

\section{Materials and Methods}

Animals. All animal experiments were performed in accordance with our institutional guidelines after obtaining the permission of the Laboratory Animal Committee. The experiments in the present study were designed to minimize the number of animals used and to minimize their suffering.

Naive adult male Wistar rats (Japan Clea, Tokyo, Japan) weighing 300-350 gm were used. They were housed four per cage in a temperature- $\left(22 \pm 2^{\circ} \mathrm{C}\right)$, humidity- $(55 \pm 10 \%)$, and light-controlled (12 hr light/dark schedule; lights on at 7:00 A.M. and off at 7:00 P.M.) environment and were fed laboratory food and water ad libitum.

$A D X$ and CORT replacement treatment. The adrenal glands were removed bilaterally under pentobarbital anesthesia ( $45 \mathrm{mg} / \mathrm{kg}$, i.p.). Either a cholesterol pellet $(100 \mathrm{mg}$, placebo) or a continuous-release CORT pellet (100 mg, $60 \mathrm{~d}$ release pellet; Innovative Research of America, Toledo, $\mathrm{OH}$ ) was implanted subcutaneously in the ADX rats to reproduce the diurnal level of circulating CORT (Holmes et al., 1997). The nocturnal level of circulating CORT was reproduced by adding CORT ( $50 \mu \mathrm{g} /$ $\mathrm{ml}$; Sigma, St. Louis, MO) to the drinking solution from 7:00 P.M. to 7:00 A.M. (Marinelli et al., 1994). Control rats underwent the same surgical procedure as the ADX rats, except that the adrenal glands were not removed (SHAM group). The SHAM rats were given a placebo pellet. The rats were allowed to recover from anesthesia and then placed in cages with both $0.9 \%$ saline (for maintaining electrolyte balance) and water for $21 \mathrm{~d}$. We then performed all experiments.

Radioimmunoassay. At the end of the experiments, the rats were killed by decapitation, and the plasma concentration of CORT was measured by radioimmunoassay. The $\left[{ }^{125} \mathrm{I}\right]$-labeled CORT $(46.3 \mathrm{kBq})$ double antibody radioimmunoassay kit for rats (Amersham Biosciences, Tokyo, Japan) was used. To displace CORT from corticosteroid-binding globulin in the plasma, the plasma was heated for $30 \mathrm{~min}$ at $60^{\circ} \mathrm{C}$. The assay was performed in duplicate at room temperature, using rabbit anti-CORT serum as the first antibody and donkey anti-rabbit serum coated on magnetizable polymer particles as the second antibody. According to the manufacturer, the cross-reactivity is low. The highest cross-reactivity was found with 11-deoxycorticosterone $(2.4 \%$ in contrast to $100 \%$ for CORT). Only ADX animals with CORT levels below the detection threshold $(5 \mathrm{ng} / \mathrm{ml})$ were included in the experiment.

Delayed nonmatch-to-sample task. The delayed nonmatch-to-sample task is sensitive to the type of working memory impairment related to PFC damage in all species of mammals (Markowitsch and Pritzel, 1977). In rodents, this task is usually performed in a T-maze (Moran, 1993; Zahrt et al., 1997; Mizoguchi et al., 2000) and is one way to evaluate spatial working memory, which is most strongly associated with the PFC (Van Haaren et al., 1985).

The delayed nonmatch-to-sample task was performed in a T-maze apparatus as described previously (Mizoguchi et al., 2000). Briefly, the animals' food allowance was maintained at $\sim 90 \%$ of normal intake until the end of the task. The rats were initially habituated to the T-maze apparatus [dimensions: stem arm, 75 length $(\mathrm{L}) \times 13$ width $(\mathrm{W}) \times 20$ height $(\mathrm{H}) \mathrm{cm}$; two branch arms, $50 \mathrm{~L} \times 13 \mathrm{~W} \times 20 \mathrm{H} \mathrm{cm}$ each] for $4 \mathrm{~d}$ until they were readily eating the food pellets located at the end of each branch arm. After habituation, the rats were trained on the delayed nonmatch-to-sample task. A trial was composed of an "information run" and a "test run." For the information run, each rat was placed in the starting box of the stem arm, with one branch arm blocked by a guillotine door; the rat was rewarded for entering either branch arm. Subsequently, for the test run, the rat was returned to the starting box, with both branch arms opened; the rat was rewarded for entering either branch arm. However, the rat was only rewarded if it entered the branch arm that was not chosen previously (correct choice, win-shift strategy). At the end of the training trial, for a total of 10 trials per session, the rats demonstrating $>90 \%$ correct choices were selected and subjected to ADX and pellet implantation.

Twenty-one days after the surgery, the rats completed the information run. After this, each rat performed the test run after several delay times $(0$, 10,30 , or $60 \mathrm{sec}$ ). Ten trials for each delay time were performed. The number of errors per test run was recorded. We also noted any anxietyrelated behaviors (e.g., piloerection, freezing, urination, and defecation) during the task operations. The rats were rated on a three point scale, whereby $0=$ normal behavior, $1=$ slight anxiety, and $2=$ severe evidence of anxiety-related behavior.

Microdialysis. The extracellular concentration of DA in the PFC was measured using an in vivo microdialysis technique in freely moving animals according to our previous report (Mizoguchi et al., 2000). Briefly, the rats were subjected to ADX and pellet implantation and were stereotaxically implanted with a guide cannula $(9 \mathrm{~mm}$ long, $0.8 \mathrm{~mm}$ outer diameter; Bioanalytical Systems, West Lafayette, IN) in the PFC (anteroposterior, +3.2; lateral, +1.2; vertical, -2.5 from the bregma) (Paxinos and Watson, 1982) under pentobarbital anesthesia ( $45 \mathrm{mg} / \mathrm{kg}$, i.p.). The rats were initially treated with Xylocaine (Fujisawa Pharmaceutical, Tokyo, Japan) to minimize pain and were monitored on a daily basis for signs of distress or infection. Twenty-one days after the surgery, the rats were restrained gently while the stylets were removed and replaced with a microdialysis probe (PC-12; tip length, $4 \mathrm{~mm}$; tip diameter, $0.5 \mathrm{~mm}$; Bioanalytical Systems). Using a microinfusion pump, Ringer's solution (in mM: $147 \mathrm{Na}, 4.0 \mathrm{~K}$, and $3.0 \mathrm{CaCl}_{2}$ ) was perfused at a rate of $0.6 \mu \mathrm{l} / \mathrm{min}$. After an equilibration period of $3 \mathrm{hr}$, the perfusate was collected every 70 $\mathrm{min}$. To examine the response to stimuli, the $\mathrm{KCl}$ concentration in Ringer's solution was raised to $100 \mathrm{~mm}$. The DA concentration in each perfusate $(35 \mu \mathrm{l})$ was measured subsequently using an HPLC system equipped with a coulometric electrochemical detector (ECD-200; Eicom, Kyoto, Japan). A reverse-phase ODS column (CA-5; Eicom) was used with a mobile phase consisting of $82 \mathrm{~mm}$ sodium phosphate, $\mathrm{pH} 6.0$, $800 \mathrm{mg} / \mathrm{l}$ sodium 1-octanesulfonate, $50 \mathrm{mg} / \mathrm{l} \mathrm{EDTA}$, and $180 \mathrm{ml} / \mathrm{l}$ methanol.

At the end of the experiments, we verified histologically the placement of the cannula in the PFC by dye infusion. This demonstrated the correct placement of the cannula in all animals.

Binding assay. Twenty-one days after ADX and pellet implantation, the $\mathrm{D}_{1}$ receptor-binding assay was performed according to our previous study (Mizoguchi et al., 2000). Briefly, the rats were killed by decapitation, and the PFC was quickly dissected on an ice plate, immediately frozen on dry ice, and stored at $-80^{\circ} \mathrm{C}$. On the day of the experiment, the tissue was homogenized in $1 \mathrm{ml}$ of ice-cold $50 \mathrm{~mm}$ Tris- $\mathrm{HCl}, \mathrm{pH} 7.4$, containing the following (in $\mathrm{mm}$ ): $120 \mathrm{NaCl}, 5 \mathrm{KCl}, 1 \mathrm{MgCl}_{2}$, and $1 \mathrm{CaCl}_{2}$, with a Teflon-glass homogenizer. The homogenates were centrifuged at $1000 \times g$ for $5 \mathrm{~min}$. The supernatants were centrifuged three times at $20,000 \times g$ for $20 \mathrm{~min}$ (resuspending the pellet each time in $1 \mathrm{ml}$ of the above buffer). The resultant pellet was resuspended, and aliquots of the suspensions were used for the determination of protein concentration according to Lowry's methods (Lowry et al., 1951). The membrane preparations $(100 \mu \mathrm{g}$ of protein in a final volume of $1 \mathrm{ml}$ ) were incubated with various concentrations of $\left[{ }^{3} \mathrm{H}\right] \mathrm{SCH} 23390$ (specific activity, $3.0 \mathrm{TBq} /$ mmol; Amersham Biosciences) in the above buffer at $37^{\circ} \mathrm{C}$ for $20 \mathrm{~min}$. The reaction was terminated by separation of the free and bound radio- 
ligands by rapid vacuum filtration through a glass filter (G/B; Whatman, Maidstone, UK). Each filter was washed three times with $3 \mathrm{ml}$ of ice-cold $50 \mathrm{~mm}$ Tris- $\mathrm{HCl}, \mathrm{pH} 7.4$, containing $1 \mathrm{~mm} \mathrm{MgCl}_{2}$. Nonspecific binding was defined by the addition of $1 \mu \mathrm{m}$ unlabeled SCH 23390. The trapped radioactivity was counted in $6.0 \mathrm{ml}$ of Cleasol I scintillation fluid (Nakalai Tesque, Osaka, Japan) by a liquid scintillation counter (LS-5000; Beckman Coulter, Fullerton, CA) at an efficiency of $45 \%$. The saturation binding data were plotted by Scatchard analysis, and the maximal number of binding sites $\left(B_{\max }\right)$ and the dissociation constant $\left(K_{\mathrm{d}}\right)$ were calculated.

Immunohistochemistry. Twenty-one days after ADX, we performed immunostaining for tyrosine hydroxylase (TH) (tyrosine 3-monooxygenase; enzyme cord number 1.14.16.2), the rate-limiting enzyme in catecholamine biosynthesis, according to our previous report (Mizoguchi et al., 2000). Briefly, the rats were perfused transcardially with $100 \mathrm{ml}$ of $0.1 \mathrm{~m}$ heparinized PBS, pH 7.4, followed by $300 \mathrm{ml}$ of $4 \%$ paraformaldehyde in $0.1 \mathrm{~m}$ phosphate buffer, $\mathrm{pH} 7.4$, under pentobarbital anesthesia ( $45 \mathrm{mg} / \mathrm{kg}$, i.p.). The brains were postfixed for $24 \mathrm{hr}$ at $4^{\circ} \mathrm{C}$ in the same fixative, cryoprotected in $30 \%$ sucrose before being frozen in powdered dry ice, and stored at $-80^{\circ} \mathrm{C}$. Sections $(30 \mu \mathrm{m})$ were cut using a freezing microtome. Free-floating tissue sections were rinsed three times with 50 mм Tris-buffered saline, $\mathrm{pH} 7.4$, containing $0.1 \%$ Triton X-100 (TBST). Endogenous peroxidase activity was blocked with $3 \%$ hydrogen peroxide in TBST, followed by incubation with $10 \%$ normal rabbit serum (NRS) in TBST for $30 \mathrm{~min}$. The sections were then incubated overnight at room temperature with monoclonal mouse antibody against TH (Boehringer Ingelheim Bioproducts, Heidelberg, Germany) diluted 1:300 in TBST containing $1 \%$ NRS. After the incubation, the sections were washed three times with TBST and were incubated for $1 \mathrm{hr}$ at room temperature with biotinylated rabbit anti-mouse IgG (Vector Laboratories, Burlingame, CA) diluted 1:200 in TBST containing 1\% NRS. The sections were washed and finally incubated with avidin-biotin-peroxidase complex (Vector Laboratories) for $1 \mathrm{hr}$ at room temperature. Control sections, in which the mouse anti-TH antibody was replaced with NRS at the same dilution, were routinely processed together with the sections of interest. The peroxidase was visualized using $0.05 \%$ diaminobenzidine hydrochloride and $0.005 \%$ hydrogen peroxide. TH-positive cells in the ventral tegmental area (VTA) were counted under a microscope on three sections for each animal, with an interval of $100 \mu \mathrm{m}$ between sections.

Infusion procedure. After the training procedure of the delayed nonmatch-to-sample task, the rats were subjected to ADX and were stereotaxically and bilaterally implanted with guide cannulas in the PFC, as described above. The rats were initially adapted to a mock infusion protocol to minimize any stress associated with the procedure until the start of infusion experiments. Twenty-one days after the surgery, infusion cannulas (PC-12; Bioanalytical Systems) that extended $1 \mathrm{~mm}$ below the guide cannula were inserted into the guide cannulas. Using a microinfusion pump, the rats then received bilateral infusions of SKF 81297 (Research Biochemicals, Natick, MA), a full $\mathrm{D}_{1}$ receptor agonist (activity comparable with DA itself) (Andersen and Jansen, 1990), at a concentration of 0 (vehicle), 1 , or $10 \mathrm{ng}$ in $0.5 \mu \mathrm{l}$ of sterile saline at a rate of 0.1 $\mu \mathrm{l} / \mathrm{min}$. Some rats received an intraperitoneal injection of vehicle or 20 $\mu \mathrm{g} / \mathrm{kg} \mathrm{SCH} 23390$ (Research Biochemicals), a $\mathrm{D}_{1}$ receptor-specific antagonist, dissolved in sterile saline, $1 \mathrm{hr}$ before the intra-PFC infusions. The cannulas remained in place for $2 \mathrm{~min}$ after the completion of the infusion. Stylets were inserted back into the guide cannulas, and the delayed nonmatch-to-sample task was commenced immediately after the infusions.

Histological verification of cannula placement by dye infusion, performed at the end of the experiments, demonstrated the correct placement of the cannula in all animals.

Statistics. The differences in the plasma CORT levels, delayed nonmatch-to-sample task, and receptor-binding assay were analyzed using one-way ANOVA. The differences in the DA release were analyzed using two-way ANOVA. Individual between-group comparisons were performed using Fisher's protected least significant difference test. The differences in the number of DA neurons were analyzed using one-way ANOVA, followed by the unpaired $t$ test.
A. Diurnal levels

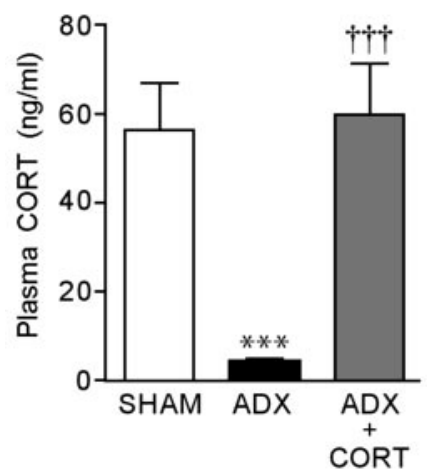

B. Nocturnal levels

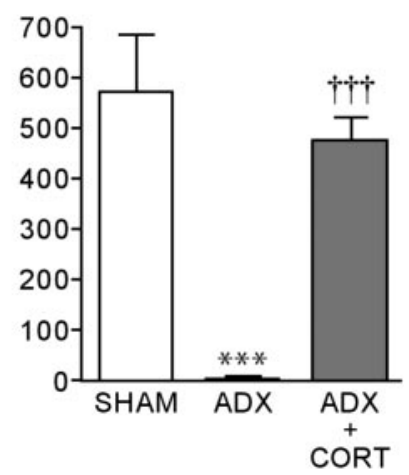

Figure 1. Plasma CORT levels after ADX and a CORT replacement treatment in rats. Each column is the mean \pm SEM of 10 rats per group. ${ }^{* * *} p<0.001$, a significant difference from SHAM control (SHAM; placebo-implanted) rats; ${ }^{+{ }^{+\dagger}} p<0.001$, a significant difference from ADX control (ADX; placebo-implanted) rats.

\section{Results}

\section{Experiment 1: plasma CORT levels}

The plasma CORT levels of the rats with SHAM, ADX, and ADX implanted with the CORT pellet are shown in Figure 1. The CORT levels significantly decreased in the ADX rats compared with the SHAM rats in both diurnal $\left(F_{(2,13)}=16.291 ; p<0.001\right)$ and nocturnal $\left(F_{(2,13)}=25.359 ; p<0.001\right)$ situations. These decreases were significantly reversed by the CORT replacement treatment (diurnal, $F_{(2,13)}=16.291, p<0.001$; nocturnal, $\left.F_{(2,13)}=25.359, p<0.001\right)$. Thus, the plasma CORT levels during this CORT replacement treatment were in the normal physiological range.

\section{Experiment 2: effect of the suppression of glucocorticoids on performance of the delayed nonmatch-to-sample task}

The performance of the delayed nonmatch-to-sample task of the rats with SHAM, ADX, and ADX implanted with the CORT pellet was evaluated using a T-maze apparatus. As shown in Figure 2, the performance accuracy was not affected by ADX or the CORT replacement treatment under the no-delay $(0 \mathrm{sec})$ condition, suggesting that ADX does not affect motivation, motor function, or long-term memory acquired previously for efficient rewarding (i.e., reference memory). Although the performance accuracy was not also affected under the 10-sec-delay condition, it markedly decreased in the ADX rats with increased delay times ( 30 and $60 \mathrm{sec})$ compared with the SHAM rats $\left(30 \mathrm{sec}, F_{(2,30)}=10.783\right.$, $\left.p<0.001 ; 60 \mathrm{sec}, F_{(2,30)}=8.137, p<0.001\right)$. These decreases in accuracy were significantly reversed by the CORT replacement treatment $\left(30 \mathrm{sec}, F_{(2,30)}=10.783, p<0.001 ; 60 \mathrm{sec}, F_{(2,30)}=\right.$ $8.137, p<0.001)$. No anxiety-related behavior was observed in any experimental group (almost all animals had a score of 0 ). Thus, the results indicated that the suppression of CORT secretion impairs the maintenance of novel short-term memory (i.e., working memory).

\section{Experiment 3: neurochemical and neurobiological studies of DA neurons in ADX rats \\ $D A$ release}

The DA release in the PFC under the basal and $\mathrm{KCl}$-stimulated conditions was evaluated using an in vivo microdialysis technique. Then, the DA release was compared between the rats with SHAM, ADX, and ADX implanted with the CORT pellet (Fig. 3). The basal DA release significantly decreased in the ADX rats com- 


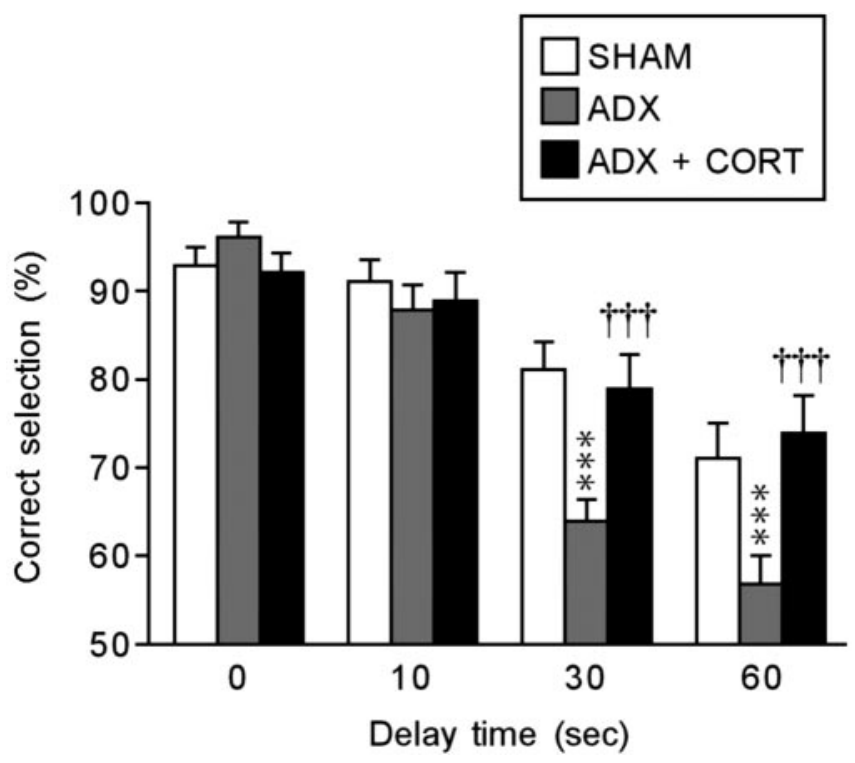

Figure 2. Effects of ADX and a CORT replacement treatment on performance of the delayed nonmatch-to-sample task with no delay $(0 \mathrm{sec})$ or several delays $(10,30$, and $60 \mathrm{sec})$. Each column is the mean \pm SEM of 10 rats per group. ${ }^{* * *} p<0.001$, a significant difference from SHAM control (SHAM; placebo-implanted) rats; ${ }^{\dagger+t} p<0.001$, a significant difference from ADX control (ADX; placebo-implanted) rats.
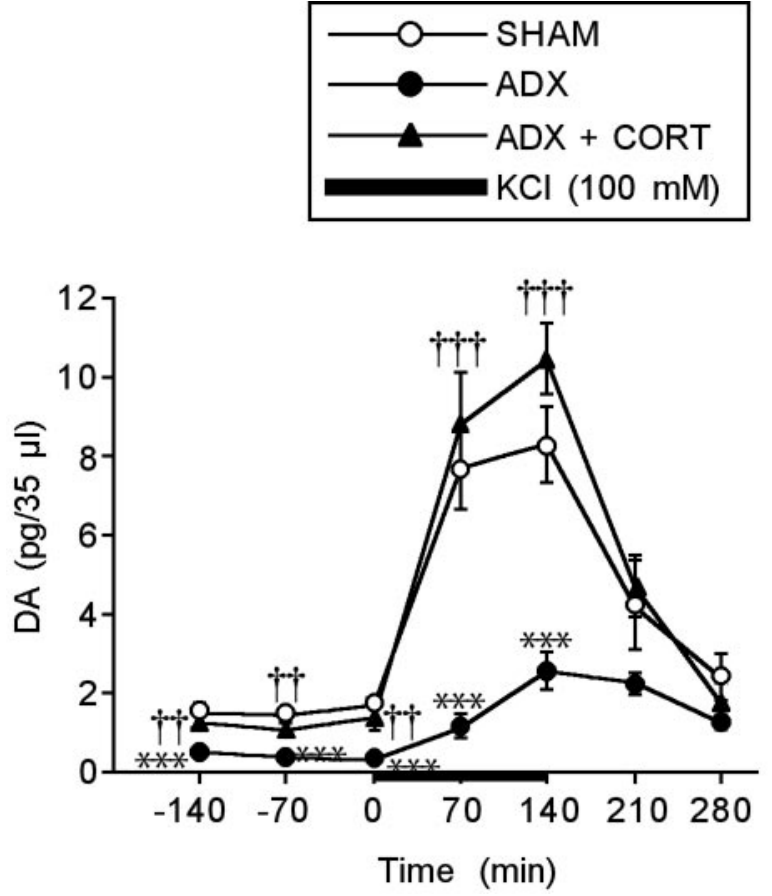

Figure 3. Effects of $A D X$ and a CORT replacement treatment on the extracellular concentration of $\mathrm{DA}$ in the PFC under the basal and $\mathrm{KCl}$-stimulated conditions. Each point is the mean \pm SEM of 8 or 10 rats per group. ${ }^{* *} p<0.001$, a significant difference from SHAM control (SHAM; placebo-implanted) rats; ${ }^{{ }^{\dagger \dagger}} p<0.01,{ }^{+t \dagger} p<0.001$, a significant difference from ADX control (ADX; placebo-implanted) rats.

pared with the SHAM rats $\left(F_{(2,23)}=12.655 ; p<0.001\right)$. A marked increase in DA release was observed in the SHAM rats under perfusion of high $\mathrm{KCl}(100 \mathrm{mM})\left(F_{(4,35)}=10.506 ; p<0.001\right)$. However, this high $\mathrm{KCl}$-induced increase in DA release was significantly attenuated in the ADX rats compared with the SHAM rats $\left(F_{(2,23)}=19.094 ; p<0.001\right)$. The ADX-induced decreases in
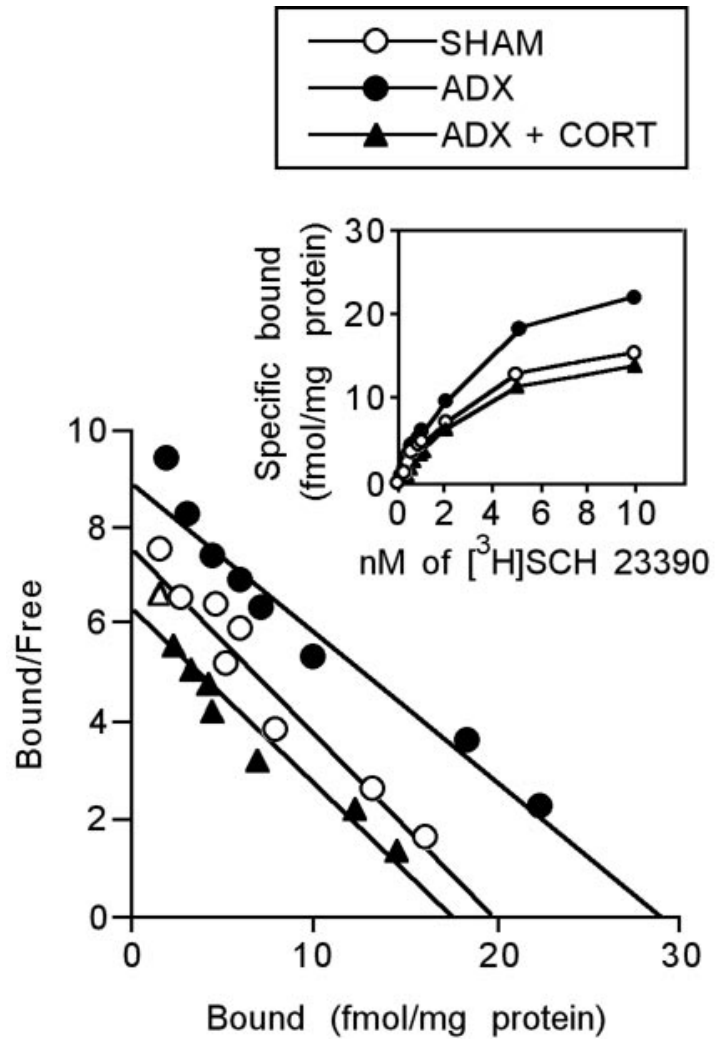

Figure 4. Saturation and Scatchard plot analyses for the $B_{\max }$ and $K_{\mathrm{d}}$ of $D_{1}$ receptors in the PFC of ADX or CORT-replaced ADX rats. Each point is the mean of 9 or 10 rats per group.

Table 1. $\left[{ }^{3} \mathrm{H}\right] \mathrm{SCH} 23390$ binding in the PFC

\begin{tabular}{lcr}
\hline & $B_{\max }$ (fmol/mg protein) & $K_{\mathrm{d}}(\mathrm{nm})$ \\
\hline SHAM & $19.4 \pm 0.8$ & $3.8 \pm 0.3$ \\
ADX & $29.0 \pm 2.4^{*}$ & $3.1 \pm 0.5$ \\
ADX + CORT & $17.6 \pm 1.3^{* *}$ & $3.6 \pm 0.4$ \\
\hline Each value is the mean \pm SEM of 9 or 10 rats per group. & \\
${ }^{*} p<0.01$, a significant difference from SHAM control (SHAM; placebo-implanted) rats; ${ }^{* *} p<0.001$, a significant \\
difference from ADX control (ADX; placebo-implanted) rats.
\end{tabular}

DA release under the basal and stimulated conditions were significantly reversed by the CORT replacement treatment (basal, $\left.F_{(2,23)}=12.655, p<0.01 ; \mathrm{KCl}, F_{(2,23)}=19.094, p<0.001\right)$. The two-way ANOVA revealed a significant $\operatorname{ADX}$ effect $\left(F_{(1,16)}=\right.$ 32.841; $p<0.001)$, a significant time effect $\left(F_{(6,16)}=31.357 ; p<\right.$ $0.001)$, and a significant $\mathrm{ADX} \times$ time interaction effect $\left(F_{(6,16)}=\right.$ $1.413 ; p<0.001)$. In addition, there was a significant CORT effect $\left(F_{(1,15)}=58.442 ; p<0.001\right)$, a significant time effect $\left(F_{(6,15)}=\right.$ 45.772; $p<0.001)$, and a significant CORT $\times$ time interaction effect $\left(F_{(6,15)}=23.574 ; p<0.001\right)$. Thus, the suppression of CORT secretion greatly decreased the DA release in the PFC.

\section{$D_{1}$ receptors}

Scatchard analysis and the saturation data of $\left[{ }^{3} \mathrm{H}\right] \mathrm{SCH} 23390$ binding for the PFC membrane preparations are shown in Figure 4. $B_{\max }$ and $K_{\mathrm{d}}$ values are presented in Table 1 . The $B_{\max }$ significantly increased in the ADX rats compared with the SHAM rats $\left(F_{(2,26)}=13.525 ; p<0.01\right)$. This increase was significantly reversed by the CORT replacement treatment $\left(F_{(2,26)}=13.525 ; p<\right.$ $0.001)$. There was no significant difference in the $K_{d}$ value between the rats with SHAM, ADX, and ADX implanted with the CORT pellet (SHAM vs ADX, $F_{(2,26)}=0.4646, p=0.241$; ADX vs ADX plus CORT, $\left.F_{(2,26)}=0.4646, p=0.371\right)$. These results 
Table 2. TH-positive cells in the VTA

\begin{tabular}{ll}
\hline & Number of TH-positive cells (per whole sections) \\
\hline SHAM & $239.4 \pm 29.7$ \\
ADX & $243.2 \pm 31.2$ \\
\hline
\end{tabular}

Each value is the mean \pm SEM of four rats per group.

indicate that $\mathrm{ADX}$ increases the density of $\mathrm{D}_{1}$ receptors without changing their affinity. However, it should be noted that increased binding of $\left[{ }^{3} \mathrm{H}\right] \mathrm{SCH} 23390$ might include the changes in serotonin type $2 \mathrm{C}\left(5-\mathrm{HT}_{2 \mathrm{C}}\right)$ receptors because Millan et al. (2001) have shown that SCH 23390 can also bind to $5-\mathrm{HT}_{2 \mathrm{C}}$ receptors.

\section{The number of DA neurons}

Because the PFC is highly innervated by dopaminergic fibers originating from the VTA (Fluxe et al., 1974), we evaluated the number of DA neurons in the VTA of the ADX rats by TH immunostaining (Table 2). The number of DA neurons in the VTA did not differ between the ADX and SHAM rats $\left(F_{(1,8)}=0.051\right.$; $p=0.826)$.

\section{Experiment 4: effect of intra-PFC infusion of SKF 81297 on} ADX-induced impairment of performance of the delayed nonmatch-to-sample task

It has been shown that DA has a beneficial effect on PFC-based working memory functions in monkeys (Brozoski et al., 1979) and rats (Simon et al., 1980; Bubser and Schmidt, 1990; Mizoguchi et al., 2000). Several studies have highlighted the importance of $D_{1}$ receptor mechanisms in this response (Sawaguchi and GoldmanRakic, 1991; Seamans et al., 1995; Mizoguchi et al., 2000). Therefore, we examined the beneficial effects of $D_{1}$ receptor stimulation in the $\mathrm{PFC}$ on the ADX-induced impairment of the performance of the delayed nonmatch-to-sample task, and the results are shown in Figure 5. The performance accuracy of the SHAM rats that received bilateral infusion of the vehicle (saline) into the PFC was similar to that of the SHAM rats in experiment 2 (Fig. 2). In addition, the performance accuracy of the ADX rats was not affected by intra-PFC infusion of saline under the no-delay and 10-sec-delay conditions, but it significantly decreased under the 30 - and 60-sec-delay conditions $\left(30 \mathrm{sec}, F_{(4,45)}=9.773, p<0.001 ; 60 \mathrm{sec}, F_{(4,45)}=11.667, p<\right.$ 0.001 ); this was also consistent with experiment 2 (Fig. 2). These results indicate that the intra-PFC infusion of saline and the cannula implantation surgery did not affect the performance accuracy of the SHAM and ADX rats. Intra-PFC infusion of 1 ng of SKF 81297 slightly but significantly ameliorated the ADX-induced decreases in the performance accuracy under the 30 -sec-delay condition $\left(F_{(4,45)}\right.$ $=9.773 ; p<0.05$ ) but not under the 60-sec-delay condition. IntraPFC infusion of $10 \mathrm{ng}$ of SKF 81297 sufficiently and significantly ameliorated the decreased accuracy under the 30- and 60-sec-delay conditions $\left(30 \mathrm{sec}, F_{(4,45)}=9.773, p<0.001 ; 60 \mathrm{sec}, F_{(4,45)}=11.667\right.$, $p<0.001$ ). The beneficial effects of $10 \mathrm{ng}$ of SKF 81297 were significantly reversed by pretreatment with intraperitoneal injection of 20 $\mu \mathrm{g} / \mathrm{kg} \mathrm{SCH} 23390$ (30 sec, $F_{(4,45)}=9.773, p<0.01 ; 60 \mathrm{sec}, F_{(4,45)}=$ $11.667, p<0.01$ ), suggesting that the actions of SKF 81297 occur at the $\mathrm{D}_{1}$ receptor rather than nonspecific drug actions. The infusion of $10 \mathrm{ng}$ of SKF 81297 into the SHAM rats and the injection of $20 \mu \mathrm{g} / \mathrm{kg}$ SCH 23390 into the SHAM and ADX rats that received the saline infusion did not affect the performance accuracy (data not shown). No anxiety-related behavior was observed in any experimental group (almost all animals had a score of 0 ). Thus, intra-PFC infusion of the $\mathrm{D}_{1}$ receptor agonist ameliorated the $\mathrm{ADX}$-induced working memory impairment in a dose-dependent manner.
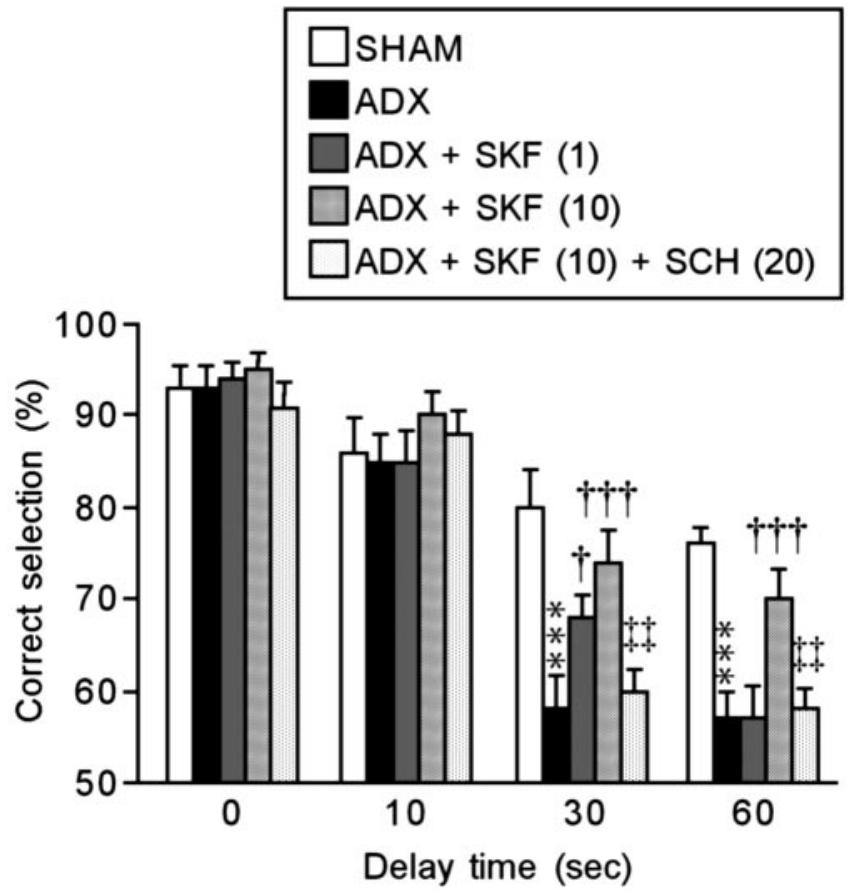

Figure 5. Effects of bilateral infusion of a $D_{1}$ receptor agonist (SKF 81297; SKF) and intraperitoneal injection of a $\mathrm{D}_{1}$ receptor antagonist ( $\mathrm{SCH} 23390$; $\mathrm{SCH}$ ) on $\mathrm{ADX}$-induced working memory impairment. The values in parentheses are in $\mathrm{ng} / 0.5 \mu \mathrm{l}$ for SKF 81297 or in micrograms per kilogram for SCH 23390. Each column is the mean \pm SEM of 10 rats per group. ${ }^{* * *} p<0.001$ a significant difference from SHAM control (SHAM; vehicle-infused) rats; ${ }^{\dagger} p<0.05,{ }^{\mathrm{tt}} p<$

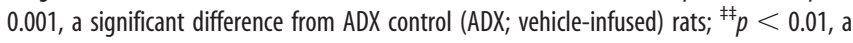
significant difference from ADX rats that received intra-PFC infusion of 10 ng of SKF 81297 $[$ ADX + SKF (10)]

\section{Discussion}

Suppression of glucocorticoids induces working memory impairment through a $\mathrm{D}_{1}$ receptor-mediated

hypodopaminergic mechanism in the PFC

The results of the delayed nonmatch-to-sample task (Fig. 2) showed that ADX did not affect reference memory but did impair working memory. Because the CORT replacement treatment maintained plasma CORT levels within the normal physiological range (Fig. 1), the beneficial effects of this treatment on the working memory impairment indicate that endogenous CORT is essential for maintaining working memory function.

The formation and maintenance of working memory are closely related to dopaminergic activity in the PFC (Simon et al., 1980; Sawaguchi and Goldman-Rakic, 1991). To confirm the involvement of the PFC dopaminergic system in the ADX-induced working memory impairment, we examined the effects that suppressing glucocorticoids had on dopaminergic transmission in the PFC. As shown in Figure 3, suppression of glucocorticoids greatly decreased dopaminergic transmission in the PFC. These results indicate that endogenous CORT is also essential for maintaining dopaminergic transmission in the PFC, and the decreased DA might contribute to the ADX-induced working memory impairment. Also, these results agree with a previous study showing that suppression of endogenous glucocorticoids by ADX greatly decreased dopaminergic transmission in the nucleus accumbens (Piazza et al., 1996).

$D_{1}$ receptors are located postsynaptically on cortical neurons (Tassin et al., 1978, 1982). Furthermore, an electrolytic lesion to decrease DA levels upregulates $\mathrm{D}_{1}$ receptors in the PFC (Tassin et al., 1982). Conversely, long-term administration of a $D_{1}$ receptor 
agonist, SKF 38393, downregulates $\mathrm{D}_{1}$ receptors in the PFC (Gambarana et al., 1995). Thus, the levels of $D_{1}$ receptors are dependent on changes in receptor stimulation. The finding that suppression of glucocorticoids upregulated $D_{1}$ receptors in the PFC (Fig. 4, Table 1) confirms at the receptor level that dopaminergic transmission was decreased (Fig. 3).

Although the mechanism by which suppression of endogenous glucocorticoids decreases dopaminergic transmission in the PFC has yet to be elucidated, glucocorticoids might increase the extracellular concentration of DA by acting directly on DA neurons that express GRs (Härfstrand et al., 1986). It is possible that glucocorticoids might increase DA synthesis at the origin of the dopaminergic innervation (i.e., VTA). However, ADX did not affect the number of DA neurons in the VTA (Table 2), which agrees with a previous study (Piazza et al., 1996). Thus, we suggest that the ADX-induced decrease in dopaminergic transmission in the PFC is not caused by decreased DA synthesis in the area from which the neurons originate, and other mechanisms should be considered. For example, glucocorticoids may decrease DA catabolism by acting as reversible monoamine oxidase inhibitors (Veals et al., 1977) or they may decrease catecholamine reuptake by inhibiting its transporters (Gilad et al., 1987; Arnsten, 2000). Alternatively, dopaminergic neuronal degeneration may occur at the synaptic level because the DA release in response to $\mathrm{KCl}$ was greatly diminished in the ADX rats (Fig. 3). This idea is supported by the observation that long-term suppression of endogenous CORT induced neuronal degeneration in hippocampal granule cells (Sloviter et al., 1989). The mechanism underlying the decrease in dopaminergic transmission should be clarified by careful and detailed experiments.

We found that intra-PFC infusion of a $D_{1}$ receptor agonist (SKF 81297) produced a dose-dependent amelioration of the ADX-induced working memory impairment (Fig. 5). The upregulation of $\mathrm{D}_{1}$ receptors in the PFC (Fig. 4, Table 1) confirms the SKF 81297 response. These results suggest that this impairment is caused by reduced $D_{1}$ receptor stimulation as a result of decreased dopaminergic transmission in the PFC (Fig. 3). Interestingly, only relatively low doses of SKF 81297 were needed to show a partial or sufficient improvement in the ADX-induced working memory impairment (i.e., 1 or $10 \mathrm{ng}$ ) compared with dosages that produce working memory impairments in normal rats (i.e., $100 \mathrm{ng}$ ) (Zahrt et al., 1997). In addition, the doses of SKF 81297 were within the proper dose-response range for the action of the $\mathrm{D}_{1}$ receptor agonist on working memory function (Zahrt et al., 1997). Thus, the present results support the hypothesis that there is a narrow range of optimal DA receptor stimulation for maintaining working memory function (Zahrt et al., 1997; Arnsten and Goldman-Rakic, 1998).

The results from this series of experiments demonstrate that suppression of endogenous glucocorticoids by ADX induces a working memory impairment through a $\mathrm{D}_{1}$ receptor-mediated hypodopaminergic mechanism in the PFC. Thus, endogenous glucocorticoids are essential for maintaining PFC cognitive function.

However, the present findings do not rule out the additional involvement of $\mathrm{D}_{2}$ and $\mathrm{D}_{3}$ receptors because these receptors also have an important role in PFC-dependent working memory (Glickstein et al., 2002; Wang et al., 2004). In addition, the hippocampus may contribute to the ADX-induced working memory impairment. Hippocampal cholinergic neurons are also involved in working memory function (Pope et al., 1987; Murai et al., 1995; Izquierdo et al., 1998). Long-term ADX induces neuronal loss in hippocampal granule cells (Sloviter et al., 1989). However,
ADX did not affect hippocampal cholinergic transmission ( $\mathrm{K}$. Mizoguchi, unpublished observations). Thus, the hippocampal cholinergic activity may be involved in the maintenance of reference memory unaffected by ADX (Fig. 2). Also, the hippocampal-PFC interaction contributes to working memory function, which is mediated by $\mathrm{D}_{1}$ receptor mechanisms (Seamans et al., 1998; Aujla and Beninger, 2001). The long delay times (30 and 60 $\mathrm{sec}$ ) involve this interaction that is not needed at short delay times $(\leq 10 \mathrm{sec})$. Thus, the role of this interaction is not ruled out.

\section{Comparison of the observations between ADX and chronically stressed rats}

Interestingly, the present results are very similar to observations of chronically stressed rats (Mizoguchi et al., 2000). Chronic stress also impaired working memory, decreased dopaminergic transmission in the PFC concomitant with no change in the number of DA neurons in the VTA, and increased $D_{1}$ receptors in the PFC. Moreover, this working memory impairment was ameliorated by intra-PFC infusion of SKF 81297. Thus, chronic stress also induced working memory impairment through a $D_{1}$ receptor-mediated hypodopaminergic mechanism in the PFC. This similarity suggests that reduced glucocorticoid actions contribute to the chronic stress-induced PFC dysfunction. Indeed, chronic stress downregulated GRs and attenuated the GRdependent response in the PFC (Mizoguchi et al., 2003). In addition, previous studies have shown that acute treatment with glucocorticoids increases dopaminergic transmission in the PFC (Imperato et al., 1989) and that transgenic mice bearing antisense RNA for GR to reduce GR actions show impaired cognitive function (Montkowski et al., 1995). Considering these findings and the present data, we suggest that a reduction in glucocorticoid actions via GR downregulation in the PFC attributable to chronic stress contributes to decreased dopaminergic transmission, which in turn causes PFC cognitive deficits. On the other hand, chronic stress-induced reduction in glucocorticoid actions may also contribute to the increase in basal levels of circulating CORT through the attenuation of the negative feedback (Mizoguchi et al., 2001, 2003). Although basal levels of circulating CORT are high in chronically stressed rats, because glucocorticoid actions would not be transmitted as a result of GR downregulation, the actions would be reduced.

\section{Clinical relevance}

Acute treatment with hydrocortisone infusion $\left(300 \mu \mathrm{g} \cdot \mathrm{kg}^{-1}\right.$. $\mathrm{hr}^{-1}$ ) facilitates working memory concomitant with PFC activation in humans (Ganguli et al., 1994). Also, PFC cognitive deficits were induced in rats after suppression of endogenous glucocorticoids. However, additional high doses of hydrocortisone infusion (600 $\mu \mathrm{g} \cdot \mathrm{kg}^{-1} \cdot \mathrm{hr}^{-1}$ ) oppositely impair working memory in humans (Lupien et al., 1999). The stress level of CORT administration induces dendritic alternations in the rat PFC (Wellman, 2001). Thus, there would be an optimal range of GR stimulation for maintaining PFC cognitive function.

Disruption of the HPA system is often observed in several stress-related neuropsychiatric disorders showing PFC cognitive deficits such as depression, schizophrenia, and Parkinson's disease (Rabey et al., 1990; Deutch, 1993; Dolan et al., 1994; Fibiger, 1995; Pariante et al., 1995; Drevets et al., 1997; PlockaLewandowska et al., 2001). In addition, depression frequently occurs in patients suffering from a stroke induced in the PFC, and a large number of these patients exhibit HPA disruption (Lipsey et al., 1985; Robinson et al., 1987). These findings suggest that PFC cognitive deficits and HPA disruption are related. Indeed, 
PFC dysfunction is observed in chronically stressed rats, concomitant with HPA disruption partially caused by GR downregulation in the PFC (Mizoguchi et al., 2000, 2001, 2003). Similar GR downregulation in the PFC is observed in patients with depression and schizophrenia (Webster et al., 2002). Considering we found that suppression of glucocorticoids (i.e., shutdown of glucocorticoid actions) induced PFC dysfunction, it is possible that reduced glucocorticoid actions in the PFC cause PFC-related cognitive deficits. Although the involvement of HPA disruption in PFC cognitive deficits in stress-related neuropsychiatric disorders has yet to be studied, the present findings lead us to hypothesize that HPA disruption contributes to PFC cognitive deficits.

In conclusion, suppression of endogenous glucocorticoids was sufficient to produce PFC dysfunction, providing evidence that endogenous glucocorticoids are essential for maintaining PFC cognitive function. The present study also yields the hypothesis that reduced glucocorticoid actions that cause HPA disruption are involved in the PFC cognitive deficits seen in stressrelated neuropsychiatric disorders.

\section{References}

Andersen PH, Jansen JA (1990) Dopamine receptor agonists: selectivity and $\mathrm{D}_{1}$ receptor efficacy. Eur J Pharmacol 188:335-347.

Arnsten AF (2000) Stress impairs prefrontal cortical function in rats and monkeys: role of dopamine $\mathrm{D}_{1}$ and norepinephrine alpha-1 receptor mechanisms. Prog Brain Res 126:183-192.

Arnsten AFT, Goldman-Rakic PS (1998) Noise stress impairs prefrontal cortical cognitive function in monkeys. Arch Gen Psychiatry 55:362-368.

Aujla H, Beninger RJ (2001) Hippocampal-prefrontocortical circuits: PKA inhibition in the prefrontal cortex impairs delayed nonmatching in the radial maze in rats. Behav Neurosci 115:1204-1211.

Brozoski TJ, Brown RM, Rosvold HE, Goldman PS (1979) Cognitive deficit caused by regional depletion of dopamine in prefrontal cortex of rhesus monkey. Science 205:929-932.

Bubser M, Schmidt WJ (1990) 6-Hydroxydopamine lesion of the rat prefrontal cortex increases locomotor activity, impairs acquisition of delayed alternation tasks, but does not affect uninterrupted tasks in the radial maze. Behav Brain Res 37:157-168.

Calabrese JR, Markovitz PJ (1991) Treatment of depression. New pharmacologic approaches. Prim Care 18:421-433.

Deutch AY (1993) Prefrontal cortical dopamine systems and the elaboration of functional corticostriatal circuits: implications for schizophrenia and Parkinson's disease. J Neural Transm 91:197-221.

Diorio D, Viau V, Meaney MJ (1993) The role of the medial prefrontal cortex (cingulate gyrus) in the regulation of hypothalamic-pituitaryadrenal responses to stress. J Neurosci 13:3839-3847.

Dolan RJ, Bench CJ, Brown RG, Scott LC, Frackowiak RS (1994) Neuropsychological dysfunction in depression: the relationship to regional cerebral blood flow. Psychol Med 24:849-857.

Drevets WC, Price JL, Simpson Jr JR, Todd RD, Reich T, Vannier M, Raichle ME (1997) Subgenual prefrontal cortex abnormalities in mood disorders. Nature 386:824-827.

Fibiger HC (1995) Neurobiology of depression: focus on dopamine. Adv Biochem Psychopharmacol 49:1-17.

Fluxe K, Hökfelt T, Johansson O, Jonnson G, Lidbrink P, Ljungdal A (1974) The origin of DA nerve terminals in limbic and frontal cortex. Evidence for mesocortical neurons. Brain Res 82:349-355.

Fuxe K, Wiksyrom AC, Gustafsson JA (1985) Mapping of glucocorticoid receptor immunoreactive neurons in the rat tel- and diencephalon using a monoclonal antibody against rat liver glucocorticoid receptor. Endocrinology 117:1803-1812.

Gambarana C, Ghiglieri O, Graziella de Montis M (1995) Desensitization of the $\mathrm{D}_{1}$ dopamine receptors in rats reproduces a model of escape deficit reverted by imipramine, fluoxetine and clomipramine. Prog Neuropsychopharmacol Biol Psychiatry 19:741-755.

Ganguli R, Mintun MA, Becker JT, Brar JS, Diehl D, Deleo M, Madoff D, Martidis A (1994) Effects of hydrocortisone infusion on rCBF in schizophrenic patients during a memory task. An $\mathrm{O}^{15} \mathrm{PET}$ study. Ann NY Acad Sci 746:385-387.
Gilad GM, Rabey JM, Gilad VH (1987) Presynaptic effects of glucocorticoids on dopaminergic and cholinergic synaptosomes. Implications for rapid endocrine-neural interactions in stress. Life Sci 40:2401-2408.

Glickstein SB, Hof PR, Schmauss C (2002) Mice lacking dopamine $\mathrm{D}_{2}$ and $\mathrm{D}_{3}$ receptors have spatial working memory deficits. J Neurosci 22:5619-5629.

Härfstrand A, Fuxe K, Cintra A, Agnati LF, Zini I, Wikstrom AC, Okret S, Yu ZY, Goldstein M, Steinbusch H, Verhofstad A, Gustafsson JA (1986) Glucocorticoid receptor immunoreactivity in monoaminergic neurons of rat brain. Proc Natl Acad Sci USA 83:9779-9783.

Holmes MC, French KL, Seckl JR (1997) Dysregulation of diurnal rhythms of serotonin $5-\mathrm{HT}_{2 \mathrm{C}}$ and corticosteroid receptor gene expression in the hippocampus with food restriction and glucocorticoids. J Neurosci 17:4056-4065.

Imperato A, Puglisi-Allegra S, Casolini P, Zocchi A, Angelucci L (1989) Stress-induced enhancement of dopamine and acetylcholine release in limbic structure: role of corticosterone. Eur J Pharmacol 165:337-339.

Izquierdo I, Izquierdo LA, Barros DM, Mello e Souza T, de Souza MM, Quevedo J, Rodrigues C, Sant'Anna MK, Madruga M, Medina JH (1998) Differential involvement of cortical receptor mechanisms in working, short-term and long-term memory. Behav Pharmacol 9:421-427.

Lange KW, Robbins TW, Marsden CD, James M, Owen AM, Paul GM (1992) L-dopa withdrawal in Parkinson's disease selectively impairs cognitive performance in tests sensitive to frontal lobe dysfunction. Psychopharmacology (Berl) 107:394-404.

Lipsey JR, Robinson RG, Pearlson GD, Rao K, Price TR (1985) The dexamethasone suppression test and mood following stroke. Am J Psychiatry 142:318-323.

Lowry OH, Rosebrough NJ, Farr AL, Randall RJ (1951) Protein measurement with the foline phenol reagent. J Biol Chem 193:265-275.

Lupien SJ, Gillin CJ, Hauger RL (1999) Working memory is more sensitive than declarative memory to the acute effects of corticosteroids: a doseresponse study in humans. Behav Neurosci 113:420-430.

Marinelli M, Piazza PV, Deroche V, Maccari S, Le Moal M, Simon H (1994) Corticosterone circadian secretion differentially facilitates dopaminemediated psychomotor effect of cocaine and morphine. J Neurosci 14:2724-2731.

Markowitsch HJ, Pritzel M (1977) Comparative analysis of prefrontal learning functions in rats, cats, and monkeys. Psychol Bull 84:817-837.

Millan MJ, Newman-Tancredi A, Quentric Y, Cussac D (2001) The "selective" dopamine D1 receptor antagonist, SCH23390, is a potent and high efficacy agonist at cloned human serotonin $2 \mathrm{C}$ receptors. Psychopharmacology (Berl) 156:58-62.

Miller AH, Spencer RL, Pulera M, Kang S, McEwen BS, Stein M (1992) Adrenal steroid receptor activation in rat brain and pituitary following dexamethasone: implications for the dexamethasone suppression test. Biol Psychiatry 32:850-869.

Mizoguchi K, Yuzurihara M, Ishige A, Sasaki H, Chui DH, Tabira T (2000) Chronic stress induces impairment of spatial working memory because of prefrontal dopaminergic dysfunction. J Neurosci 20:1568-1574.

Mizoguchi K, Yuzurihara M, Ishige A, Sasaki H, Chui DH, Tabira T (2001) Chronic stress differentially regulates glucocorticoid negative feedback response in rats. Psychoneuroendocrinology 26:443-459.

Mizoguchi K, Ishige A, Aburada M, Tabira T (2003) Chronic stress attenuates glucocorticoid negative feedback: involvement of the prefrontal cortex and hippocampus. Neuroscience 119:887-897.

Montkowski A, Barden N, Wotjak C, Stec I, Ganster J, Meaney M, Engelmann M, Reul JM, Landgraf R, Holsboer F (1995) Long-term antidepressant treatment reduces behavioural deficits in transgenic mice with impaired glucocorticoid receptor function. J Neuroendocrinol 7:841-845.

Moran PM (1993) Differential effects of scopolamine and mecamylamine on working and reference memory in the rats. Pharmacol Biochem Behav 45:533-538.

Murai S, Saito H, Masuda Y, Odashima J, Itoh T (1995) AF64A disrupts retrieval processes in long-term memory of mice. NeuroReport 6:349-352.

Pariante CM, Nemeroff CB, Miller AH (1995) Glucocorticoid receptors in depression. Isr J Med Sci 31:705-712.

Paxinos G, Watson C (1982) The rat brain in stereotaxic coordinates. New York: Academic.

Piazza PV, Barrot M, Rougé-Pont F, Marinelli M, Maccari S, Abrous N, Simon H, le Moal M (1996) Suppression of glucocorticoid secretion and 
antipsychotic drugs have similar effects on the mesolimbic dopaminergic transmission. Proc Natl Acad Sci USA 93:15445-15450.

Plocka-Lewandowska M, Araszkiewicz A, Rybakowski JK (2001) Dexamethasone suppression test and suicide attempts in schizophrenic patients. Eur Psychiatry 16:428-431.

Pope CN, Ho BT, Wright AA (1987) Neurochemical and behavioral effects of $\mathrm{N}$-ethyl-acetylcholine aziridinium chloride in mice. Pharmacol Biochem Behav 26:365-371.

Rabey JM, Scharf M, Oberman Z, Zohar M, Graff E (1990) Cortisol, ACTH, and beta-endorphin after dexamethasone administration in Parkinson's dementia. Biol Psychiatry 27:581-591.

Robinson RG, Bolduc PL, Price TR (1987) Two-year longitudinal study of poststroke mood disorders: diagnosis and outcome at one and two years. Stroke 18:837-843.

Sawaguchi T, Goldman-Rakic PS (1991) $\mathrm{D}_{1}$ dopamine receptors in prefrontal cortex: involvement in working memory. Science 251:947-950.

Seamans JK, Floresco SB, Phillips AG (1995) Selective impairment on a delay radial arm task following local administration of a selective $D_{1}$, but not a $\mathrm{D}_{2}$, antagonist into the prefrontal cortex. Soc Neurosci Abstr 21:1942.

Seamans JK, Floresco SB, Phillips AG (1998) $D_{1}$ receptor modulation of hippocampal-prefrontal cortical circuits integrating spatial memory with executive functions in the rat. J Neurosci 18:1613-1621.

Simon H, Scatton B, le Moal M (1980) Dopaminergic A-10 neurons are involved in cognitive functions. Nature 206:140-151.

Sloviter RS, Valiquette G, Abrams GM, Ronk EC, Sollas AL, Paul LA, Neubort S (1989) Selective loss of hippocampal granule cells in the mature rat brain after adrenalectomy. Science 243:535-538.

Steckler T, Holsboer F, Reul JM (1999) Glucocorticoids and depression. Baillières Best Pract Res Clin Endocrinol Metab 13:597-614.

Tanda G, Carboni E, Frau R, Di Chiara G (1994) Increase of extracellular dopamine in the prefrontal cortex: a trait of drugs with antidepressant potential? Psychopharmacology (Berl) 115:285-288.

Tassin JP, Bockaert J, Blanc G, Stinus L, Thierry AM, Lavielle S, Prémont J, Glowinski J (1978) Topographical distribution of dopaminergic innervation and dopaminergic receptors of the anterior cerebral cortex of the rats. Brain Res 154:241-251.

Tassin JP, Simon H, Hervé D, Blanc G, le Moal M, Glowinski J, Bockaert J (1982) Non-dopaminergic fibers may regulate dopamine-sensitive adenylate cyclase in the prefrontal cortex and the nucleus accumbens. Nature 259:696-698.

Van Haaren F, De Bruin JP, Heinsbroek RP, Van de Poll NE (1985) Delayed spatial response alternation: effects of delay-interval duration and lesions of the medial prefrontal cortex on response accuracy of male and female Wistar rats. Behav Brain Res 18:41-49.

Veals JW, Korduba CA, Symchowicz S (1977) Effect of dexamethasone on monoamine oxidase inhibition by iproniazid in rat brain. Eur J Pharmacol 41:291-299.

Wang M, Vijayraghavan S, Goldman-Rakic PS (2004) Selective $\mathrm{D}_{2}$ receptor actions on the functional circuitry of working memory. Science 303:853-856.

Webster MJ, Knable MB, O’Grady J, Orthmann J, Weickert CS (2002) Regional specificity of brain glucocorticoid receptor mRNA alterations in subjects with schizophrenia and mood disorders. Mol Psychiatry 7:985-994.

Wellman CL (2001) Dendritic reorganization in pyramidal neurons in medial prefrontal cortex after chronic corticosterone administration. J Neurobiol 49:245-253.

Zahrt J, Taylor JR, Mathew RG, Arnsten AFT (1997) Supranormal stimulation of $D_{1}$ dopamine receptors in the rodent prefrontal cortex impairs spatial working memory performance. J Neurosci 17:8528-8535. 